\title{
Rapid Reductive-Carboxylation of Secondary Amines, One Pot Synthesis of $\mathrm{N}^{\prime}-\left(4-{ }^{11} \mathrm{C}\right.$-Methyl)Imipramine
}

\author{
SIYA RAM, RICHARD E. EHRENKAUFER and DOUGLAS M. JEWETT \\ Cyclotron/PET Facility, Division of Nuclear Medicine, The University of Michigan Medical Center, \\ Ann Arbor, MI 48109, U.S.A.
}

(Received 3 September 1985; in revised form 20 November 1985)

\begin{abstract}
A new rapid high yield synthesis of radiolabeled $\mathrm{N}^{\prime}-\left(4-^{11} \mathrm{C}-\right.$ methyl $)$ imipramine has been developed using a reductive-carboxylation approach, in which " $\mathrm{CO}_{2}$ is reacted with either $\mathrm{N}$ '-trimethylsilyldesimipramine or $\mathrm{N}^{\prime}$-lithium derivative of desimipramine, followed by lithium aluminum hydride reduction, to give no carrier added or carrier added ${ }^{\prime C} \mathrm{C}$-labeled imipramine respectively. The final product is characterized by chromatographic and spectroscopic methods.
\end{abstract}

\section{Introduction}

Radioalkylation of secondary amines by direct fixation of $\left[{ }^{\prime \prime} \mathrm{C}\right]$ carbon dioxide under moderate reaction conditions is an attractive alternative to the most commonly used alkylating agents such as $\left[{ }^{1} \mathrm{C}\right]$ methy] iodide $\left({ }^{11} \mathrm{CH}_{3} \mathrm{I}\right)$ and $\left[{ }^{11} \mathrm{C}\right]$ formaldehyde $\left(\mathrm{H}^{11} \mathrm{CHO}\right)$, which are, in principle, themselves derived from $\left[{ }^{1 "} \mathrm{C}\right] \mathrm{carbon}$ dioxide. For example, recently, two independent syntheses of $\mathrm{N}^{\prime}-\left(4-{ }^{11} \mathrm{C}\right.$-methyl)imipramine based on the reductive methylation ${ }^{(14)}$ and methylation $^{(5)}$ of desimipramine using $\mathrm{H}^{11} \mathrm{CHO} / \mathrm{NaBH}_{4}$ and ${ }^{11} \mathrm{CH}_{3} \mathrm{I}$ respectively had been reported in the literature. Recently direct fixation of $\left[{ }^{14} \mathrm{C}\right]$ carbon dioxide into amines has been reported by Pichat et al ${ }^{(6)}$ In our ongoing program, we were interested in direct fixation of ${ }^{11} \mathrm{CO}_{2}$ into various organic molecules, which are potentially of biological interest such as palmitic acid, $\alpha$-amino acids, etc. for positron emission tomography studies. We therefore developed a new reductive-carboxylation approach, in which secondary amines were carboxylated with $\left[{ }^{11} \mathrm{C}\right]$ carbon dioxide to their carbamate esters. In situ lithium aluminium hydride reduction ${ }^{(7)}$ of these esters, provided $\mathrm{N}-\left[{ }^{[1} \mathrm{C}\right]$ methyl derivatives in very good yield. ${ }^{(8)}$ Using this approach, we synthesized a potent antidepressant, $\mathrm{N}^{\prime}$-(4- ${ }^{11} \mathrm{C}$-methyl)imipramine from desimipramine, which is described in this paper. The procedure is very simple and casily adaptable to automation of the synthesis for human studies.

\section{Experimental}

\section{Materials and methods}

The starting material, N'-(4-trimethylsilyl)desimipramine (2) was prepared by refluxing desimipramine (DMI)-HCl salt (1) with 1,1,1,3,3,3-hexamethyldisilazane (HMDS). A standard solution of N'-TMS derivative of DMI was prepared by dissolution in dry THF, which was previously distilled over $\mathrm{LiAlH}_{4} /\left(\mathrm{C}_{6} \mathrm{H}_{5}\right)_{3} \mathrm{C}-\mathrm{Cl}$. Chemicals: $1.55 \mathrm{M}$ solution of $\mathrm{n}$ - $\mathrm{BuLi}$ in $\mathrm{n}$-hexane, $0.5 \mathrm{M}$ solution of $\mathrm{LiAlH}_{4}$ in THF, were purchased from the Aldrich Chemical Company. The synthetic apparatus outlined in Fig. 1, consists of the following parts (a) liquid-nitrogen trap, for the initial trapping of " ${ }^{~} \mathrm{CO}_{2}$ in a small stainless steel loop. (b) A $1 \mathrm{~mL}$ conical shaped reaction vial, fitted with a Teflon-coated septum and connected to an argon gas cylinder. (c) A $10-\mathrm{mL}$ two-neck conical-shaped reaction flask fitted with rubber septa. (d) A 25-mL Erlenmeyer conical flask containing dry $\mathrm{Na}_{2} \mathrm{SO}_{4}$. Purity of radiolabeled and cold imipramine was checked by HPLC, two Varian silica gel $\mathrm{Si}-10$ guard columns connected in series [size $4.6 \mathrm{~mm} \times 3 \mathrm{~cm}$, each, which were connected with a small stainless steel tube], with $\mathrm{CH}_{2} \mathrm{Cl}_{2}: \mathrm{MeOH}: 58 \%$ $\mathrm{NH}_{4} \mathrm{OH}(135: 15: 0.12)$ as the eluant. Identification of the products was confirmed by TLC (E. Merck, silica gel $60 \mathrm{~F}_{254}$ ) and Analtech, silica gel (GHLF plates) using mobile phase $\mathrm{CH}_{2} \mathrm{Cl}_{2}: \mathrm{MeOH}: 58 \% \quad \mathrm{NH}_{4} \mathrm{OH}$ 


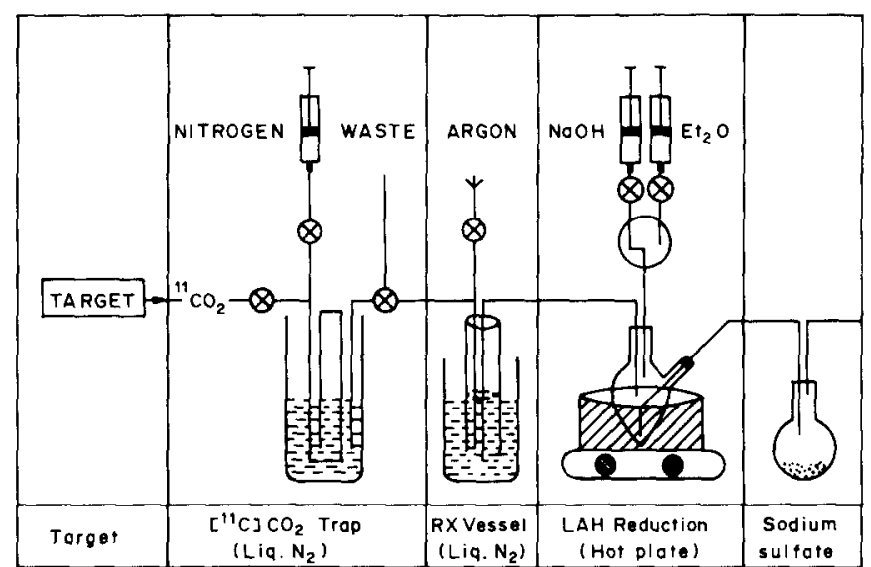

Fig. 1. Apparatus for the synthesis of $N^{\prime}-\left(4-{ }^{-1} \mathrm{C}\right.$-methyl)imipramine.<smiles>CNC(C)N1c2ccccc2CCc2ccccc21</smiles>

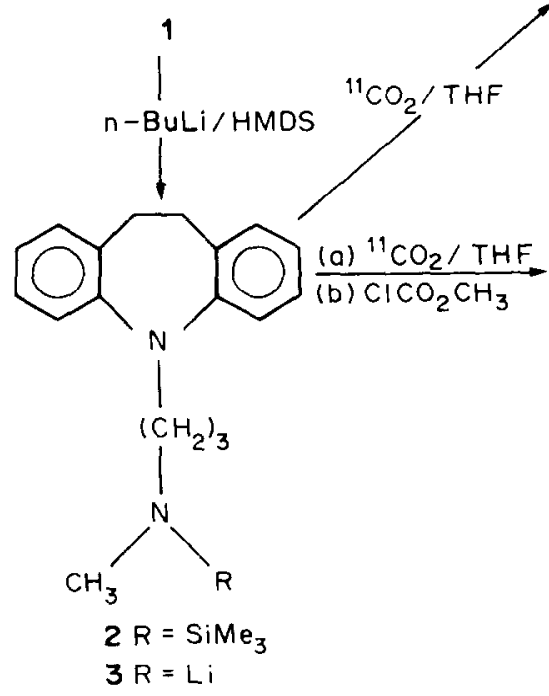

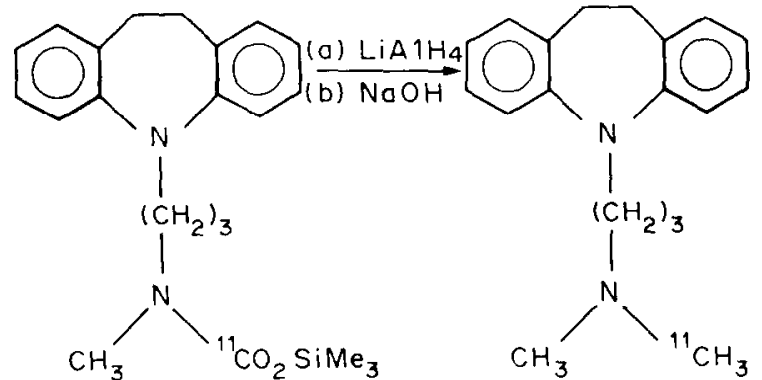

4

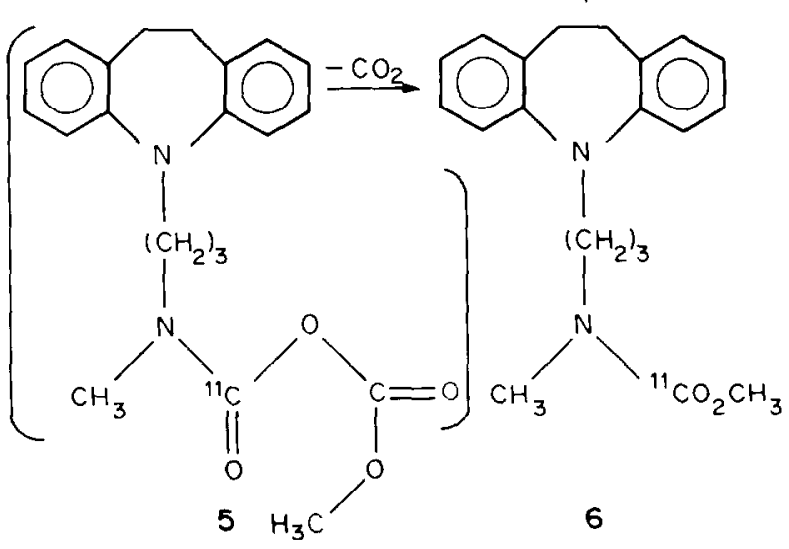

Fig. 2. CA and NCA synthesis of $\mathrm{N}^{\prime}-\left(4-{ }^{11} \mathrm{C}\right.$-methyl $)$ imipramine.

(9:1:3-drops). The " $\mathrm{CO}_{2}$ was obtained by the ${ }^{14} \mathrm{~N}(\mathrm{p}, \alpha){ }^{11} \mathrm{C}$ nuclear reaction using the University of Michigan CS-30 (The Cyclotron Corporation) cyclotron. The target gas containing mainly " $\mathrm{CO}_{2}$ was used directly without further processing.

\section{Synthetic steps}

The "C-radiolabeled imipramine was synthesized by two independent routes.
(A) No-carrier added synthesis of $N^{\prime}-\left(4-{ }^{\prime \prime} C\right.$-methyl $)$ imipramine

The synthetic steps are outlined in Fig. 2.

Synthesis of $N^{\prime}$-(4-trimethylsilyl)desimipramine (2). A suspension of DMI-HCl salt $(1,0.5 \mathrm{~g})$ in HMDS $(5.0 \mathrm{~mL})$ was stirred at reflux temperature for $12-15 \mathrm{~h}$. The excess HMDS was removed under reduced pressure on a steam bath using a rotary evaporator. The resulting oil was dried under high 
vacuum and dissolved in dry THF $(20 \mathrm{~mL})$ and stored in a sealed vial under argon pressure. This solution was used as a stock solution for further reactions.

Synthesis of $N^{\prime}-\left(4^{\prime \prime} C\right.$-methyl)imipramine (7). $\left[{ }^{11} \mathrm{C}\right]$ carbon dioxide produced by the ${ }^{14} \mathrm{~N}(\mathrm{p}, \alpha)^{11} \mathrm{C}$ nuclear reaction was quantitatively trapped in a stainless steel loop (3.2-mm o.d.) half immersed in liquid nitrogen. After collection, the loop was warmed up to room temperature and $\left[{ }^{11} \mathrm{C}\right]$ carbon dioxide was purged into the reaction mixture vial, which contained $\mathrm{N}^{\prime}$-TMS-derivative of DMI (2) in dry THF $(86 \mu \mathrm{mol}, 0.7 \mathrm{~mL})$. The resulting reaction mixture was heated in a heating block at $55-60 \mathrm{C}$ for 8-10 min. The reaction mixture was then transferred with help of positive pressure of argon, to a $10-\mathrm{mL}$, two-neck conically-shaped reaction flask, which contained $0.1 \mathrm{M}-\mathrm{LiAlH}_{4}$ solution in dry THF $(3.5 \mathrm{~mL})$. The resulting reaction mixture was stirred with heating at $60-65^{\circ} \mathrm{C}$ for $10 \mathrm{~min}$. After cooling the mixture was decomposed with $6.25 \mathrm{~N}-\mathrm{NaOH}$ solution (approx. $2 \mathrm{~mL}$ ). The product was diluted with diethyl ether $(2 \times 5 \mathrm{~mL})$ and the organic layer was decanted. The combined ether layers were dried over $\mathrm{Na}_{2} \mathrm{SO}_{4}$ and again decanted to a round-bottom flask. Evaporation of the ether layer on a rotary evaporator, provided "C-labeled imipramine, which contained some residual unreacted DMI starting material.

Purification of $N^{\prime}-\left(4-{ }^{\prime \prime} C\right.$-methyl)imipramine. The impure imipramine was dissolved in $1 \mathrm{~mL}$ of $\mathrm{CH}_{2} \mathrm{Cl}_{2}: \mathrm{MeOH}: 58 \% \quad \mathrm{NH}_{4} \mathrm{OH} \quad(135: 15: 0.12)$ and loaded on to a silica gel column [column size $12 \times 1.35 \mathrm{~cm}$, silica gel, E. Merck, $2.0 \mathrm{~g}, 230-400$ mesh] and the compound was cluted with $\mathrm{CH}_{2} \mathrm{Cl}_{2}: \mathrm{MeOH}: 58 \% \mathrm{NH}_{4} \mathrm{OH}$ system $(10 \mathrm{~mL})$ by applying gentle pressure through $50-\mathrm{cm}^{3}$ syringe. The fractions 4-6 (1.5 mL, each) which contain almost all the radioactivity were pooled. The maximum activity was found in fraction No. 5. The purity of the thus purified imipramine was checked by radio-HPLC using two guard columns (Si-10, size $4.6 \mathrm{~mm} \times 3 \mathrm{~cm}$, each) connected in series by a small stainless steel tube and $\mathrm{CH}_{2} \mathrm{Cl}_{2}: \mathrm{MeOH}: 58 \% \mathrm{NH}_{4} \mathrm{OH}(135: 15: 0.12)$ as an eluant with flow rate of $1 \mathrm{~mL} / \mathrm{min}$. Detection of imipramine is performed by u.v. absorption at $254 \mathrm{~nm}$. Imipramine is retained for $2.21 \mathrm{~min}$ and desimipramine for $4.75 \mathrm{~min}$. The purity of purified, radiolabeled imipramine was $99.5 \%$ as confirmed by TLC.

Identification and quality control. The above pooled radioactivity fractions were evaporated. The u.v. and chromatographic behaviour (HPLC, TLC and GLC) were identical with authentic sample.

(B) Carrier-added synthesis of $N^{\prime}-\left(4-{ }^{\prime \prime} C\right.$-methyl $)-$ imipramine

Cold synthesis of imipramine. Method I: Synthesis of $N^{\prime}$-(4-carbomethoxy)desimipramine (6). $\mathrm{n}-\mathrm{BuLi}$ $(9.0 \mathrm{mmol}, 5.81 \mathrm{~mL}$ of $1.55 \mathrm{M}$ solution of $\mathrm{n}-\mathrm{BuLi}$ in n-hexane) was added to a stirred suspension of
DMI-HCl salt $(1,0.906 \mathrm{~g}, 3.0 \mathrm{mmol})$ in dry THF $(20 \mathrm{~mL})$ at $-78 \mathrm{C}$ and stirring was continued for $30 \mathrm{~min}$ at $-78 \mathrm{C}$, then methyl chloroformate $(0.46 \mathrm{~mL}, 6.0 \mathrm{mmol})$ was added. The resulting reaction mixture was stirred $4-5 \mathrm{~h}$ at $-78 \mathrm{C}$ and $10 \mathrm{~h}$ at room temperature. Reaction progress was monitored by TLC [silica gel, $\left.\mathrm{CH}_{2} \mathrm{Cl}_{2}: \operatorname{MeOH}(9: 1)\right]$. When the reaction was complete, the solvent was evaporated under reduced pressure. The residue was redissolved in $5 \mathrm{~mL}$ of $\mathrm{CH}_{2} \mathrm{Cl}_{2}: \mathrm{MeOH}(9: 1)$ and chromatographed over silica gel column [column size, $2 \times 35 \mathrm{~cm}$, silica gel, E. Merck, $20 \mathrm{~g}, 230-400 \mathrm{mesh}$. The product was eluted with $\mathrm{CH}_{2} \mathrm{Cl}_{2}$. Fractions containing the desired product were pooled and evaporated under reduced pressure to give 6 as an oil, yield $0.93 \mathrm{~g}(95.4 \%)$. i.r. (neat) $3018,2950-20,2840$, $1705,768,750 \mathrm{~cm} \quad{ }^{1} ;{ }^{1} \mathrm{H}$ NMR $\left(\mathrm{CDCl}_{3}\right) \delta 1.47-2.10$ $\left(\mathrm{t}, 2 \mathrm{H}, \mathrm{C}-\mathrm{CH}_{2}-\mathrm{C}\right), 2.73$ (s, 3H, N-CH $), 2.97-4.45$ (m, $11 \mathrm{H}, \quad \mathrm{N}-\mathrm{CH}_{2}-\mathrm{C}-\mathrm{C}, \quad \mathrm{CO}_{2} \mathrm{CH}_{3},-\mathrm{CH}_{2}-\mathrm{CH}_{2}-$,$\mathrm{CH}_{2} \mathrm{~N}-\mathrm{CO}$ ), 6.64-7.40 (bs, $8 \mathrm{H}, \mathrm{Ar}-\mathrm{H}$ ). Anal. Calc'd for: $\mathrm{C}_{20} \mathrm{H}_{24} \mathrm{~N}_{2} \mathrm{O}_{2}, \mathrm{C}, 74.05 ; \mathrm{H}, 7.46 ; \mathrm{N}, 8.63$, Found C, $73.94 ; \mathrm{H}, 7.36 ; \mathrm{N}, 8.71 . R_{\mathrm{f}}$ values of product and desimipramine were 0.68 and 0.47 respectively, [silica gel, Analtech plates, $\left.\mathrm{CH}_{2} \mathrm{Cl}_{2}: \mathrm{MeOH}(98: 2)\right]$

Method II: Synthesis of $N^{\prime}$-(4-carbomethoxy)desimipramine (6) using $\mathrm{CO}_{2} . \mathrm{n}-\mathrm{BuLi}(3.0 \mathrm{mmol}$, $1.94 \mathrm{~mL}$ of $1.55 \mathrm{M}$ solution of $\mathrm{n}-\mathrm{BuLi}$ in $\mathrm{n}$-hexane) was added to a stirred suspension of desimipramine I ICl salt $(1,0.302 \mathrm{~g}, 1.0 \mathrm{mmol})$ in dry THF $(20 \mathrm{~mL})$ and stirring was continued for $30 \mathrm{~min}$ at $-78^{\circ} \mathrm{C}$. Dry $\mathrm{CO}_{2}$ was then bubbled into the reaction mixture for $5 \mathrm{~min}$ at $-78^{\circ} \mathrm{C}$ and $15 \mathrm{~min}$ at $55 \mathrm{C}$, followed by addition of methyl chloroformate $(2.0 \mathrm{mmol})$. The resulting reaction mixture was stirred at reflux temperature for $30 \mathrm{~min}$, the solvent was evaporated under reduced pressure and the resulting residue was purified by column chromatography over silica gel [column size $2 \times 35 \mathrm{~cm}$, E. Merck silica gel, $12 \mathrm{~g}$, 230-400 mesh] using $\mathrm{CH}_{2} \mathrm{Cl}_{2}$ as an eluant. The fractions containing the desired product were pooled and evaporated under reduced pressure to give $\mathbf{6}$, an oil; yield $0.31 \mathrm{~g}(93 \%)$. The material was identical in all respects (spectroscopically and analytically) to compound 6 as prepared by Method I.

In situ reduction of $N^{\prime}$-(4-carbomethoxy)desimipramine (6) to imipramine (7). $\mathrm{N}^{\prime}$-(4-carbomethoxy)desimipramine $(6,1.0 \mathrm{mmol})$ in dry $\mathrm{THF}(20 \mathrm{~mL})$ was prepared as described in Method II. To the above stirred solution, $\mathrm{LiAlH}_{4}(0.4 \mathrm{~g})$ was added slowly under argon atmosphere and resulting reaction mixture was refluxed for $30 \mathrm{~min}$. The excess of $\mathrm{LiAlH}_{4}$ was decomposed with $6.25 \mathrm{~N}-\mathrm{NaOH}$ solution. Diethyl ether $(20 \mathrm{~mL} \times 2)$ was added and the ether layer was decanted. The combined ether layer was dried over $\mathrm{Na}_{2} \mathrm{SO}_{4}$ and evaporated under reduced pressure to give 7 as an oil in $79 \%$ yield, which was identical to the authentic imipramine except having some impurity of n-pentanol, as detected by GLC analysis. The above products were isolated and characterized for identification purposes. 
Table 1. Radioanalytical data of the $N \cdot\left(4-{ }^{11} \mathrm{C}-\right.$ methyl $)$ imipramine

\begin{tabular}{cccc}
$\begin{array}{c}\text { Experiment } \\
\text { number }\end{array}$ & $\begin{array}{c}\text { Radiochemical } \\
\text { yield }(\%)\end{array}$ & $\begin{array}{c}\text { Radiochemical } \\
\text { purity }(\%)\end{array}$ & $\begin{array}{c}\text { Total amount of } \\
\text { ["C]carbon dioxide } \\
\text { trupped (mCi) }\end{array}$ \\
\hline $1^{14}$ & 67.56 & 95.83 & $3.22^{\mathrm{h}}$ \\
$2^{3}$ & 88.92 & 97.40 & 51.23 \\
$4^{4}$ & 77.65 & 99.47 & 65.23 \\
\hline
\end{tabular}

"No carricr added synthesis.

${ }^{\mathrm{b}} \mathrm{A}$ tracer experiment was studied.

Carrier added synthesis.

Synthesis of $N^{\prime}$-(4- ${ }^{\prime \prime} C$-methyl)imipramine (7). nBuLi $(0.58 \mathrm{~mL}, 0.9 \mathrm{mmol}, 1.55 \mathrm{M}$ solution of $\mathrm{n}-\mathrm{BuLi}$ in n-hexane) was added to a $10-\mathrm{mL}$. two neck conically-shaped reaction flask, fitted with rubber septa, containing a suspension of desimipramine- $\mathrm{HCl}$ salt $(1,97 \mathrm{mg} .0 .3 \mathrm{mmol})$ in dry THF $(6.0 \mathrm{~mL})$. Stirring was continued for $30 \mathrm{~min}$ at $-78 \mathrm{C} .{ }^{11} \mathrm{CO}_{2}$ was then purged into the reaction mixture. The reaction mixture was heated at $55 \mathrm{C}$ for $5 \mathrm{~min}$, and methyl chloroformate $(0.035 \mathrm{~mL}, 0.45 \mathrm{mmol})$ was added via a syringe. The resulting reaction mixture was stirred and heated at $50-65 \mathrm{C}$ for $10 \mathrm{~min}$. $\mathrm{LiAlH}_{4}$ (100 $\mathrm{mg}$ ) was added under an argon atmosphere and heating was continued for additional $15 \mathrm{~min}$. The reaction mixture was cooled and excess of $\mathrm{LiAlH}_{4}$ was decomposed with $6.25 \mathrm{~N}-\mathrm{NaOH}$ solution (approximately $1-1.5 \mathrm{~mL}$ ). The organic layer was decanted into a conical flask containing dry $\mathrm{Na}_{2} \mathrm{SO}_{4}$, the residue was washed with diethyl ether $(5 \mathrm{~mL} \times 2)$ and decanted again to the conical flask. The combined ether layer was decanted into a $25-\mathrm{mL}$ roundbottom flask. Radio TLC analysis results showed only one major radio peak, which corresponds to imipramine. The radiochemical yield was $64 \%$ based on radio TLC purity of the crude reaction mixtures. A minor radioacitivty peak $(<10 \%)$ identified as n-pentanol (resulting from carboxylation of n-BuLi, followed by $\mathrm{LAH}$ reduction) was also observed.

\section{Results and Discussion}

In general the reductive-carboxylation procedure has the following possible distinet advantages over current radioalkylation procedures.

(1) Unlike ${ }^{11} \mathrm{CH}_{3} \mathrm{I}$ or $\mathrm{H}^{11} \mathrm{CHO},{ }^{11} \mathrm{CO}_{2}$ is directly available from the cyclotron target for on-line synthesis, without further processing.

(2) The use of ${ }^{11} \mathrm{CO}_{2}$ directly as the radio-precursor can result in a higher specific activity product, since no reduction or oxidation steps are involved in radiolabeled precursor preparation. which may introduce "cold" " ${ }^{2} \mathrm{CO}_{2}$ *

* LAH may contain traces of ${ }^{2} \mathrm{CO}_{2}$ salts in the reduction of "${ }^{~} \mathrm{CO}_{2}$ to MeOH.

In the oxidation of "C-MeOH to " $\mathrm{CH}_{2} \mathrm{O},{ }^{\prime 2} \mathrm{C}$ may be introduced from residual traces of organic solvent (i.e. THF etc.) used in the LAH reduction step.
The overall manual production of $\mathrm{N}^{\prime}-\left(4-{ }^{11} \mathrm{C}\right.$ methyl)imipramine required approximately $45 \mathrm{~min}$ from the end of bombardment. The trapping of [" $\mathrm{C}] \mathrm{CO}_{2}$ from the target gas in the substrate solution required approximately $5 \mathrm{~min}$. The radiochemical yield and purity for carried added synthesis were $64 \%$ and $85 \%$ based on radio TLC of the crude reaction mixtures, which were not optimized and are based on the single experiment. In the case of no carried added synthesis, the radiochemical yield and purity for purified imipramine were 77 and $99.5 \%$ respectively, which were also not optimized. The results of four experiments are presented in Table 1 . The $R_{f}$ values of synthesized products checked with authentic compounds and other physicochemical data were also similar to authentic sample. HPLC analysis demonstrated a total of I $\mu \mathrm{mol}$ of cold imipramine was produced based on the single experiment, however no attempts werc made to purify hydrocarbon traces from the target gas. The radiochemical purity of ${ }^{11} \mathrm{C}$-labeled imipramine was confirmed by HPLC. Specific activity of the $\left[{ }^{11} \mathrm{C}\right]$ imipramine was calculated to be $50 \mathrm{mCi} / \mu \mathrm{mol}$ [at the end of cyclotron bombardment (EOB)]. This specific activity represents neither maximum " $\mathrm{CO}_{2}$ production nor optimized synthesis time, both of which will determine the attainable specific activity. The $1 / \mu \mathrm{mol}$ of cold imipramine produced, however, is comparable to or slightly greater than cold amounts reported elsewhere ${ }^{(3.5)}$ and likely represents the amount of ${ }^{12} \mathrm{CO}_{2}$ produced in this system.

\section{Conclusions}

High specific activity and high purity $\mathrm{N}^{\prime}$-(4- ${ }^{11} \mathrm{C}$-methyl)imipramine can be readily synthesized in excellent radiochemical yield from $\left[{ }^{11} \mathrm{C}\right] \mathrm{CO}_{2}$ by a reductive-carboxylation method. The yield and purity can be optimized and time can be shortened by automation of the reaction. The apparatus is very simple for automation of the synthesis. The reductive-carboxylation approach is easily adaptable to the synthesis of other potentially important radiopharmaceuticals such as promazine, guanifexine, nicotine, etc.

Acknowledgements-Research was supported by $\mathrm{NCI}$ training grant No. 5-T32-CA-09015 and by NINCDS grant No. PO1-NS-15655. The authors are thankful to Dr Keith 
Mulholland for his valuable suggestions, Roger Lininger for the proton irradiations and Ms Linder Markham for her assistance in the preparation of this manuscipt. We are greatly indebted to Dr T. Pruss, Revlon Health Care for the generous gift of desimipramine.

\section{References}

1. Comar D., Mazjere M., Marazano C. and Raynaud C. J. Nucl. Med. 16, 521 (1975).

2. Berger G., Maziere M. and Comar D. J. Labeled Compd. Radiopharm. 16, 97 (1979).

3. Berger G., Maziere M., Knipper R., Prenant C. and Comar D. Int. J. Appl. Radiat. Isot. 30, 393 (1979).

4. Maziere M., Berger G. and Comar D. In Application of Nuclear and Radiochemistry (Eds Lambrecht R. M. and
Morcos N.), pp. 251-270. (Pcrgamon Press, Ncw York, 1982).

5. Denutte H., Goethals P., Cattoir H., Bogaert M., Vandewalle T., Vandercasteele C., Jonckheere J. and Leenher A. D. J. Nucl. Med. 24, 1185 (1983).

6. (a) Frideling J. P. and Pichat L. Int. Symp. on the Synthesis and Applications of Isotopically Labelled Compounds. 6-11 June 1982, Kansas City, MO, U.S.A.; (b) Frideling J. P. Ph.D. Thesis. Insertion of ${ }^{14} \mathrm{C}$-carbon dioxide between the $N$-Si bond of silylated amines. 4 May 1982. CEN Saclay 9119/Gif/Yvette Cedex, France (In French).

7. Holland H. L. and Johnson G. B. Tetrahedron Lett. 3595 (1979)

8. Ram S. and Ehrenkaufer R. E. Tetrahedron Lett. 26, 5367 (1985) 